\title{
In search of a new public for scientific exhibitions or festivals: the lead of casual visitors
}

\author{
Fabienne Crettaz von Roten
}

\begin{abstract}
This article examines the public at a science exhibition or festival and tries to determine whether casual visitors are a means of expanding the audience. According to a Swiss survey of public attitudes towards science (2005), the non-public of a science exhibition or festival is distinguished by demographics such as gender and education (more female and less educated), cultural practices (less frequent) and attitudes towards science (less positive). Considering the Swiss science festival of 2009, casual visitors differ from intentional ones in terms of sociodemographic aspects and scientific cultural practices; on the other hand, casual visitors are close to intentional ones in terms of non-scientific cultural practices and attitudes towards science. Consequently, casual visitors are one way of increasing audiences.
\end{abstract}

\section{Context}

\section{The origin of science festivals}

To bring science closer to society, ${ }^{1}$ various types of events have been implemented since the Eighties: lectures, public debates, cafés scientifiques, open doors at academic institutions, science festivals, participatory procedures such as consensus conferences and collectives of patients, etc. These events seek to reach different audiences by proposing different models of scientific communication: the purpose of spreading information following the simple linear model prevail at lectures, while the purpose of dialogue following the two-dimensional diffusion model at cafés scientifiques. ${ }^{2}$ As regards widening the reached public, certain authors have claimed that visiting a museum or a scientific institution may give rise to fears of a strange world, to the loss of one's usual landmarks, and they have stressed the importance of the spatial dimension: "the choice of meeting place contributes to the achievement of the objectives of the event or activities". Some events have therefore been held in less confined, busy spaces, such as public squares, malls, railway stations, cafés, and so on. Recalling the nineteenth-century science fairs and great exhibitions, and inspired by the success of music or cinema festivals, the modern form of the science festival was invented in 1989 in Edinburgh from which it then spread throughout Europe, America, Asia and Africa. ${ }^{4}$ The science festival is characterized by criteria of unity of time and place, by a variety of events of which it is composed and by an informal and festive atmosphere. Science festivals have been held at different levels: local, national and international.

In Switzerland, the multiplication of these events is part of a specific national political context: direct democracy allows citizens ${ }^{5}$ to submit initiatives on any subject, as long as the required number of signatures is reached. Initiatives have often concerned science, and the one in 1998 on genetic engineering gave rise to controversial public debates and strongly mobilized the scientific community. Following this vote, the Fondation Science et Cité was created to organize events that would bring together science and society: lectures, cafés scientifiques, film shows and science festivals. The Fondation has tried different approaches for the three festivals that it has held so far: the open doors style in 2001, mediation through art in 2005 and the occupation of a public, indeed popular space in $2009 .^{6}$ Each of the events held after 2001 sought to extend the public by appealing to art lovers in 2005 and curious onlookers in 2009. 


\section{The different kinds of public: target public, public, non-public, potential public}

The organizers of a science festival, like those of any cultural event, define their target audiences in advance, often focussing on subgroups of the population who are supposedly less interested in science, namely women, young people and less educated. This is an essential step because the whole population cannot be unilaterally defined as a target. ${ }^{7}$ A posteriori, assessments establish whether these objectives have been achieved: as regards number of visitors, target audience, visitor satisfaction, impact on visitors, etc. If these assessments describe the public, they set up the rest of the population as non-public, so that the multiplication of the quantitative approach to visitor studies contributed to the reification of the concept of non-public: "Assignment to a negative category leads to the reification of a statistical regularity, and even more to essentialization and substantialization".

The concept of the non-public first appeared in France in 1968 with reference to the theatre during a meeting between stage directors and social science researchers: for each cultural event, on the one hand its public is defined, either actual or potential, and on the other its non-public, that is "human hugeness composed of all those who do not yet have any access to the cultural phenomenon, or any immediate likelihood to do so." 9 This notion was later researched by sociologists of culture and communication, ${ }^{10}$ however it gives rise to certain problems in feeding the imagination (the existence of a boundary between public and non-public) and in freezing visions (the universe of the non-audience belongs to the domain of certainty - permanent exclusion - whereas that of the potential public belongs to the domain of probability - transient exclusion). In practice, does not the deterministic assumption attached to the original notion of non-public make any effort to attain it vain? This notion was mobilized more for high culture than for mass culture. So if applied to events of scientific mediation, it has not been much studied in this context, ${ }^{11}$ which perhaps indicates the importance of the project for increasing popular access to scientific culture: if we consider that no one is excluded, what is the use of studying this flawed notion with such a deterministic assumption.

As regards science sociologists, and in particular from Public Understanding of science, ${ }^{12}$ the view of a homogeneous public for science has been replaced by the view of different publics: "There is not necessarily one homogeneous public but many and heterogeneous publics that act in social contexts and shift their attention and levels of knowledge with the rise and fall of a variety of issues". ${ }^{13}$ The depreciation of a public that was considered ignorant gave way, first of all, to an idealized view of a public with flawless desires for information and participation, then secondly to a more qualified view of publics expressing different levels of interest and participation depending on the time, the place or the circumstances. ${ }^{14}$ Other researchers have shown how scientists build their own visions of the public and assign him a role (that of naive spectator, supporter of science, witness, participant, etc..) and how these constructions influence the nature of the relationship between science and society. ${ }^{15}$

\footnotetext{
Aim

Science festival visitors have been studied extensively. ${ }^{16}$ They are often regarded as a social entity, as a group with a unity and consistency, which differenciates itself only from the rest of the population that is absent: "the public is really a public because it differs from those who feel neither concerned nor attracted". ${ }^{17}$ These studies therefore seek to understand the opposition between the public and the nonpublic. However, the public is formed by very heterogeneous audiences, and it is necessary to study these different audiences since this especially allows us to see whether a specific implementation of a festival has brought in a new public.

The aim of this paper is to provide parts of information about these various audiences, with a case study of Switzerland: first of all we will present the characteristics of exhibition or festival non-public by means of a survey of the population's attitudes to science and, secondly, we will study how the casual visitors to the science festival in 2009 were similar to intentional visitors to the event, to determine whether casual visitors set up a new public.
} 


\section{Method}

This paper is based on two Swiss surveys concerning the relations between science and society, carried out by the Observatoire Science, Politique et Société of Lausanne University:

- The survey on the population's attitudes to science and technology, Eurobarometer 63.1, conducted in 32 countries (25 European member states, 4 candidate countries and 3 EFTA countries, including Switzerland) from 3 January to 15 February 2005. In each country, about 1000 face-to-face interviews were held, except in Luxembourg, Cyprus, Malta and Iceland (500). The interviewees were selected using a multi-stage random technique on the adult population (15 years and over). With this sample size, the margin of error is $3.1 \%$ maximum nationwide. The report is available at the address: http://ec.europa.eu/public_opinion/archives/ebs/ebs_224_report_en.pdf. ${ }^{18}$

- The evaluation of the 3rd edition of the Science et Cité festival, Basecamp09, held during the summer of 2009 in six towns in Switzerland. Organized in collaboration with the Swiss Academy of Natural Sciences and affiliated to the United Nations' International Year of Planet Earth, this festival focused on the general theme of the environment and climate change.

In four towns, an assessment system of the festival was implemented and, in the end, 1738 visitors accepted to reply to a relatively short questionnaire. ${ }^{19}$ The data analysis shows that the demographic profile of the public is relatively close to that of the Swiss population. The proportion of women $(52 \%)$ was substantially the same as in Switzerland (51\%). The average age of 38 and the distribution in different age groups indicates a rather young public compared with the mean age and the population pyramid in Switzerland (on average 41 years). On the other hand, the educational level of visitors is much higher than that of the general population, with $44 \%$ of people with tertiary education (university, polytechnic, etc.) against $14 \%$ in the Swiss population. ${ }^{20}$ The motivations most often mentioned by visitors were the desire to be informed (46\%), a general interest in science (40\%) and, further behind, the festival theme (27\%); in addition to these expected motivations, it was noted that nearly a quarter of the visitors said they were just passing by $(23 \%)$. The overall satisfaction of visitors was very high $(86 \%$ indicated they were very or fairly satisfied), this percentage is similar for men and women and in all age groups and all levels of education. The report is available at the address: www.unil.ch/osps.

\section{Results}

\section{Characteristics of the non-public of a science exhibition or festival}

In 2005 , only $15 \%$ of the people who replied to the Swiss survey on attitudes to science had visited a science exhibition or festival in the last twelve months. ${ }^{21}$ If the percentage of non-public is high $(85 \%)$, it must be pointed out that great variations were recorded across the sociodemographic categories. The proportion of non-public is highest:

- $\quad$ among women (88\% against $82 \%$ among men),

- $\quad$ among the elderly (88\% among those over 55, against $82 \%$ among $15-24$ years, $84 \%$ among 25 39 years, $84 \%$ among $40-54$ years),

- $\quad$ among the less educated (90\% of those who completed their studies before age $15,86 \%$ between 16 and 19 years, $79 \%$ after 20 years and $80 \%$ for those still studying)

- $\quad$ and among the occupational categories between house person, or unemployed (respectively $93 \%$ and $91 \%$ against $79 \%$ self-employed and $80 \%$ among students).

So the ideal of democratisation is not only not achieved at the level of sex, education and social and occupational categories (these three factors are significant ${ }^{22}$ ), but is not influenced by age. These results confirm the influence of cultural and economic capital on cultural practices observed by many foreign surveys; ${ }^{23}$ they support the study of the Cite des Sciences et de l'Industrie (Paris), indicating that the probability of visiting the event was linked to geographic proximity and to education. ${ }^{24}$

We note that the non-public of a science exhibition is rather impervious to the various types of scientific cultural offers $(77 \%$ of the non-public at a science exhibition have not visited a museum of science and technology) and is relatively indifferent to any cultural offers $(67 \%$ of the non-public at a science exhibition have not visited an art museum, $63 \%$ a public library, $57 \%$ a zoo or aquarium). Nearly two 
thirds of the non-public combine the factors of distance from cultural practices, indicating a cultural distance in the broad sense.

The distance between the non-public and scientific culture ${ }^{25}$ is also found in the science knowledge quiz that was part of the survey ${ }^{26}$ : the non-public had a mean number of correct answers lower than the public (9.1 against 10.0) and while $46 \%$ of the non-public gave between 10 and 13 correct answers, the percentage was $66 \%$ among the public.

To get to know these non-visitors better, the reasons for this lack of interest are important, but our survey covered only the absence of a visit to a museum of science and technology. On this point, the interviewees mentioned firstly the lack of time (42\%), then lack of interest $(26 \%)$ and distance $(15 \%){ }^{27}$ So not visiting such a museum is not mainly the result of a lack of information (7\% replied "I don't know where these museums are") or of their being too complex (5\% replied "I don't understand them"), but rather of competition with other ways of spending their free time.

Social psychology, particularly the theory of planned behaviour, suggests that behaviour is predicted by social norms and attitudes related to behaviour. ${ }^{28}$ The public of a science exhibition or festival has more positive attitudes to science than the non-public (Table 1): $57 \%$ of the public emphasized the benefits of science compared to its harmful effects against $41 \%$ of the non-public; $78 \%$ of the public support scientific research against $66 \%$ of the non-public; $48 \%$ of the public believe that science and technology will help eliminate hunger and poverty against $33 \%$ of the non-public; only $28 \%$ of the public rejects the importance of science in everyday life against $40 \%$ of the non-public. ${ }^{29}$

\begin{tabular}{|c|c|c|}
\hline & Non-public & Public \\
\hline The benefits of science are greater than any harmful effects it may have. & $41.3(18.9)$ & $56.9(8.6)$ \\
\hline $\begin{array}{l}\text { Even if it brings no immediate benefits, scientific research which adds to } \\
\text { knowledge should be supported by Government. }\end{array}$ & $66.2(18.5)$ & $78.3(14.1)$ \\
\hline $\begin{array}{l}\text { Science and technology will help eliminate poverty and hunger around } \\
\text { the world. }\end{array}$ & $32.9(43.8)$ & $48.3(34.5)$ \\
\hline In my daily life, it is not important to know about science. & $40.1(43.9)$ & $28.1(59.6)$ \\
\hline $\begin{array}{l}\text { The public is sufficiently involved in decisions about science and } \\
\text { technology. }\end{array}$ & $35.3(47.3)$ & $32.6(48.9)$ \\
\hline Scientists put too little effort into informing the public about their work. & $51.1(20.4)$ & $45.7(31.5)$ \\
\hline
\end{tabular}

Table 1. Attitudes toward science and technology of non-public and public of a science exhibition/festival (\% agree (\% don't agree)).

On the other hand, there is no significant difference concerning the degree of implication of the population in decisions about science and technology and the efforts made by scientists to provide information.

\section{Characteristics of the casual visitors to the science festival in 2009}

Designed as a travelling base camp, the 2009 science festival included a central device consisting of several multiform tents and containers with exhibitions and events that travelled from town to town, setting up the display on a public square. By pitching their tents in these busy places, the organizers also hoped to reach an audience that would normally never visit an event, institution or museum related to science.

In this paper, we define as casual visitors those who answered "I was just passing" when asked the reason for their visit, as against those who chose to come to the festival, intentional visitors. We try to determine whether casual visitors are distinguished from intentional visitors. In other words, our aim is to study whether the festival location helped attract a new public to the festival.

In 2009 , we observed $23 \%$ of casual visitors; due to the festival location in public places that were more or less central and more or less busy, this percentage varied from one town to another: up to $29 \%$ in Berne, $21 \%$ in Zürich and Neuchâtel and $18 \%$ in Lugano.

The profile of intentional and casual visitors differs according to certain sociodemographic characteristics (Table 2). There were more males among casual visitors than among intentional ones 
(50\% against 47\%). People in the intermediate age groups (18-24 and 25-39) are more represented among casual visitors (respectively $20 \%$ and $37 \%$ against $12 \%$ and $24 \%$ ). People more educated ${ }^{30}$ seem more likely to be tempted by a chance visit to a science festival: the percentage of interviewees with tertiary education is much higher among casual visitors than intentional ones ( $51 \%$ against $42 \%)$.

\begin{tabular}{|l|ll|}
\hline & Casual visitors & Intentional visitors \\
\hline Men & 49.9 & 47.1 \\
Women & 50.1 & 52.9 \\
-17 years & 5.7 & 11.6 \\
$18-24$ years & 19.7 & 12.0 \\
$25-39$ years & 36.6 & 24.4 \\
$40-54$ years & 25.4 & 37.9 \\
Over 55 years & 12.6 & 14.1 \\
Secondary I & 5.7 & 8.6 \\
Secondary II & 42.9 & 49.8 \\
Tertiary & 51.4 & 41.6 \\
\hline
\end{tabular}

Table 2. Sociodemographic profiles of casual and intentional visitors (in \%).

Our analyses also show significant differences between casual and intentional visitors at the level of cultural practices related to science but not related to art (Table 3): casual visitors are less likely to have visited a museum of science and technology, a scientific theme park, or a scientific event in the last twelve months, whereas the differences are minimal for zoos, public libraries, art museums, theatres, concerts and festivals.

\begin{tabular}{|l|cc|}
\hline & Casual visitors & Intentional visitors \\
\hline Museum of science and technology & 58.3 & 51.5 \\
Scientific theme park & 81.2 & 76.8 \\
Other scientific events & 78.1 & 71.9 \\
Zoo, aquarium & 43.4 & 44.7 \\
Public library & 34.9 & 35.0 \\
Art museum & 38.2 & 40.4 \\
Theatre, concert of classical music, ballet & 37.3 & 36.2 \\
Other festival & 29.9 & 28.9 \\
\hline
\end{tabular}

Table 3. Cultural practices of casual and intentional visitors (in \% not having attended in the last 12 months).

Moreover, casual and intentional visitors have rather similar attitudes towards science: the difference is not significant for the first three items, but the attitude of casual visitors is significantly more critical of the efforts made by scientists to inform the population (Table 4). ${ }^{31}$

\begin{tabular}{|l|lc|}
\hline & Casual visitors & Intentional visitors \\
\hline $\begin{array}{l}\text { The benefits of science are greater than any harmful } \\
\text { effects it may have. }\end{array}$ & $65.5(12.3)$ & $66.5(10.1)$ \\
$\begin{array}{l}\text { In my daily life, it is not important to know about } \\
\text { science. }\end{array}$ & $18.8(66.4)$ & $18.9(67.9)$ \\
$\begin{array}{l}\text { The population is sufficiently involved in decisions } \\
\text { about science and technology. }\end{array}$ & $22.1(53.5)$ & $22.4(54.4)$ \\
$\begin{array}{l}\text { Scientists put too little effort into informing the } \\
\text { population about their work. }\end{array}$ & $48.2(25.5)$ & $43.3(28.2)$ \\
\hline
\end{tabular}

Table 4. Attitudes of casual and intentional visitors towards science and technology (\% agree (\% don't agree)). 
Lastly, there is no significant difference in overall satisfaction among casual and intentional visitors: the percentage of very satisfied was close to $50 \%$ and of very or fairly satisfied close to $95 \%$ in both cases. Likewise, there is no significant difference in the rate of satisfaction concerning the six themes of the event related to the issue of environmental protection, climate change and sustainable development: "Climate change", "Resources", "Earth and Health", "Earth and Life", "Natural Hazards" and "The Depths of the Earth".

\section{Conclusions}

In the last 50 years, science and technology have changed many aspects of our daily life ranging from health to work, food and social relationships. In addition, certain developments (nuclear energy, genetically modified organisms, nanotechnology) have become the subject of controversy and public debate. In this context, communication between science and society must rely on all possible types of mediation. Various types of event have been implemented since the Eighties: lectures, public debates, cafés scientifiques, open doors at academic institutions, science festivals, etc. Science festivals have been highlighted, because they bring science and society together in a non-intimidating, festive framework, thus being able to reach a wider audience. Nowadays, most European countries organize science festivals (Austria, UK, France, Belgium, Sweden, Switzerland, etc.) and the need to produce results also concerns these events of scientific mediation. They have received negative criticism including that of aiming only at a minority of highly educated people who are already convinced of the benefits of science, and of only offering a celebration of science and not a true dialogue between science and society, centred on various topics that interest the population, for only a true dialogue can bring in other audiences apart from those already convinced.

Researchers in communication and in the Public understanding of science have involved different notions of the public in their research: public, target public, non-public, actual public, potential public. However, the question of the possibility of expanding the circle of people participating in events bringing together science and society is still a valid one. This paper attempts to provide some answers based on two Swiss studies outlining the relationship between science and society.

Firstly, according to a survey held in $2005,85 \%$ of Swiss had not visited a science exhibition or festival in the last twelve months. This non-public is distinguished from the public by its sociodemographic characteristics, cultural practices and attitudes towards science. Our results agree with several foreign studies, including an English one showing that visitors to science festivals tend to be recruited among the group of "technophiles", characterized by a great belief in the importance of science and the increased opportunities that science can offer future generations; these visitors profile as male, young and well educated, whereas the group with a "Not for me" attitude is characterized by a rejection of the importance of science, less interest in political and scientific subjects, and an older, less educated profile. ${ }^{32}$ We must, however, point out that the limitation of the visit to the last twelve months gives an arbitrary character to the boundary between public and non-public: according to this definition, this nonpublic certainly includes a part of the potential public.

Secondly, the location of a science festival in a central public space, as recommended by many authors, increases the proportion of casual visitors, that is of those who visit it by chance. In our assessment of the 2009 festival, about a quarter of visitors are casual against $7 \%$ in the 2005 edition. In addition, casual visitors differ from intentional visitors in sociodemographic terms and in cultural practices regarding science. It appears that it is not so much science that makes the casual visitor (same attitudes to science as the intentional visitor), but rather the scientific culture or the way scientists provide information. Consequently, the operational choices for the science festival of 2009 actually brought in a new public for science by completing the cultural offer and introducing another way of informing the public. However, it is not certain that the satisfaction of the casual visitor, which is just as high as that of the intentional visitor, is sufficient to make him a future visitor to a science exhibition or festival. It would be interesting to investigate whether a positive experience of scientific cultural practice has a lasting impact.

If casual visitors differ from intentional visitors, are they necessarily a non-public? A comparative analysis indicates that casual visitors are quite different from the non-public in sociodemographic terms (more male and more educated, while the non-public is more female and less educated) and in their attitude towards science (positive attitudes, while the non-public is more negative towards science). Casual visitors are therefore a limited way of reducing the non-public and it can be assumed that they are 
recruited more among the potential public. This result does not mean a failure of the festival as a form of scientific mediation, because the temporal nature of the cultural socialization process must be taken into account: the first science festival was held in Switzerland in 2001 and, at intervals of four years, it takes some time to become part of cultural practices. By reaching members of the potential public, the latest edition of the festival has already been a success, although in future editions it will have to integrate the plurality of public better and succeed in circulating and even bringing back different audiences.

Our study is limited to science festivals in Switzerland and it would be important to compare the reasons for visits in other countries. In addition, our study raises two points: on the one hand, the fact that they made the visit says nothing about the quality, or about the impact of the visit, and on the other hand the type of public/non-public imposes two kinds of limits - of reification and stigmatization - that must be kept in mind. It is therefore important to devote more research - both quantitative and qualitative, according to sociological and psychological approaches - to gain a better understanding of what determines participation or non-participation in scientific mediation events.

Translation by Alexandra M. Speirs

\section{Notes and references}

${ }^{1}$ Changes in public attitudes toward science in connection with certain controversial scientific developments and environmental crises have led scientific institutions to reflect on their relationship with society and to propose solutions for bringing science closer to society. For example, Royal Society (1985), The Public Understanding of Science, London, Royal Society; American Association for the Advancement of Science (AAAS) (1988), Science, Technology, and Society: Emerging Relationships, Washington, AAAS ; European Commission (EC) (2002), Science and society : Action plan, EC, Luxembourg.

2 For the different models of communication, see for example J. Gregory and S. Miller (1998), Science in Public: Communication, Culture, and Credibility, New York, Plenum Press.

3 J. Riise (2008), Bringing Science to the Public, in D. Cheng, M. Claessens, T. Gascoigne, J. Metcalfe, B. Schiele, S. Shi (eds), Communicating Science in Social Contexts, Brussels, Springer, 301-309: p. 302. Certain publications even indicate what type of place is best suited for reaching that type of public: Research Councils UK (2002). Dialogue with the Public. Practical Guidelines. London, Research Councils.

4 Cf. D. Raichvarg (1993), Science et spectacle: figures d'une rencontre, Nice, Z'editions; J. Nolin, F. Bragesjö and D. Kasperowski (2003), Science Festivals and Weeks as Spaces for OPUS, in: U. Felt (ed), Optimising Public Understanding of Science and Technology: Final Report, Vienna, University of Vienna, 271-282.

5 In order not to complicate the text, all terms referring to individuals have not been given in feminine form, but they refer to both men and women.

${ }^{6}$ See the Internet site of the Fondation www.science-et-cite.ch/projekte/festival/fr.aspx.

7 According to Felt (2003), when designating everyone as the target audience there is the risk of not reaching anyone in the end. U. Felt (2003), When society encounter "their" sciences: conceptualising the relationships between sciences and publics, in: U. Felt (ed), Optimising Public Understanding of Science and Technology: Final Report, Vienna, University of Vienna, 16-46.

8 L. Fleury (2008), Sociologie de la culture et des pratiques culturelles, Paris, Armand Colin, p. 35.

9 Déclaration de Villeurbanne drawn up by Fr. Jeanson in 1968 and resumed in his book of 1973 L'action culturelle dans la cité, Paris, Editions du Seuil, p. 119.

${ }^{10}$ See for example the following edited collections: A. Ancel and P. Pessin (2004), Les non publics, Les arts en réception, Paris, L'Harmattan; D. Jacobi and J. Luckerhoff (2010), A la recherche du "non-public », Loisir et société 32(1).

${ }^{11}$ Cf. A. de Mengin (2001), La notion de "non-public » confrontée aux études auprès des non-visiteurs de la Cité des sciences et de l'industrie, in O. Donnat and S. Octobre (dir), Les publics des équipements culturels. Méthodes et résultats d'enquêtes, Paris, Les travaux du DEP, 187-201; H. Featherstone, et al. (2009). Defining Issue-based Publics for Public Engagement, Climate Change as a Case Study, Public Understanding of Science 18(2): 214-228.

${ }^{12} \mathrm{By}$ this we mean a set of empirical researches and practices focused on the relationship between science and society. This approach cannot be reduced in any way to the deficit model which postulates that the public does not like science because it is not sufficiently informed.

${ }^{13}$ E. Einsiedel (2000), Understanding "publics" in the public understanding of science, in M. Dierkes and C. von Grote (dir.). Between understanding and trust: the public, science and technology, Amsterdam, Harwood Academic Publishers, 205-215, p. 207.

${ }^{14}$ Cf. U. Felt (2000), Why should the public "understand" science? A historical perspective on aspects of the public understanding of science, in M. Dierkes and C. von Grote (dir.). Between understanding and trust: the public, science and technology, Amsterdam, Harwood Academic Publishers, 7-38; E. Einsiedel (2007), Editorial: of publics and science, Public Understanding of Science 16(1): 5-6.

${ }^{15}$ Felt (2003), p. 43.; R. Holliman and E. Jensen (208), (In)authentic sciences and (im)partial publics: (re)constructing the science outreach and public engagement agenda, in R. Holliman et al. (dir.), Investigating science communication in the information age: Implications for public engagement and popular media, New York, Oxford University Press, 35-51.

${ }^{16}$ Cf. P. Ghosh (2001), A Festival Comes of Age, Science \& Public Affairs, October 2001, 18-19; U. Felt and A. Müller (2003), Science Week and festivals in Austria. An experiment in science communication, in U. Felt (dir.), Optimising Public 
Understanding of Science and Technology, Vienna, University of Vienna, 283-286; L. Grant (2003), Evaluation of the 2003 Cheltenham Festival of Science, Liverpool, The University of Liverpool ; F. Crettaz von Roten and O. Moeschler (2007), Is Art a "Good " Mediator in a Science Festival?, JCOM 06(03): A2, retrieved Nov 22007 available at: http://jcom.sissa.it/archive/06/03/Jcom0603(2007)A02/; Office of Science and Technology (OST) (2007), UK Science Festivals: PEST or Not?, London, OST.

${ }^{17}$ D. Jacobi and J. Luckerhoff (2010), p. 13.

${ }^{18}$ For the Swiss results, see F. Crettaz von Roten (2006), Les Suisses et les sciences en 2005 : structure et facteurs explicatifs des attitudes, in J.-P. Leresche, M. Benninghoff, F. Crettaz von Roten, and M. Merz (eds.), La fabrique des sciences. Des institutions aux pratiques, Lausanne, PPUR, 283-304.

${ }^{19}$ It concerned the reasons for and details of the visit, degree of satisfaction, sociodemographic profile, cultural practices, attitudes toward science.

${ }^{20}$ However, this percentage is not as high as in 2005 (F. Crettaz von Roten and O. Moeschler (2007)).

${ }^{21}$ On the other hand, $26 \%$ had visited a museum of science and technology and $36 \%$ an art museum in the last twelve months.

${ }^{22}$ The Chi-square test of independence gave a p-value lower than 0.05 .

${ }^{23}$ P. Bourdieu and A. Darbel (1969), L'amour de l'art. Les musées d'art européens et leur public, Paris : L'Harmattan ; O. Donnat (1998), Les pratiques culturelles des Français, Paris: La documentation française ; P. DiMaggio and T. Mukhtar (2004), Arts Participation as Cultural Capital in United States, 1982-2002 : Signs of Decline, Poetics, 32, 169-194.

${ }^{24}$ A. De Mengin (2001).

${ }^{25}$ The hypothesis tested here is the application to science of the results obtained by Bourdieu and Darbel (1969) showing a relationship between the possession of aesthetic skills and the propensity to appreciate art.

${ }^{26}$ Namely a series of thirteen statements on scientific facts to which the person had to answer true or false, for example the centre of the earth is very hot; the sun revolves around the earth; lasers work by converging sound waves. The one-way analysis of variance gave a p-value lower than 0.05 .

${ }^{27}$ F. Crettaz von Roten (2010), Publics de la culture et publics de la science via les enquêtes sur la population, in R. Gaillard (ed), Exposer des idées, questionner des savoirs. Les enjeux d'une culture de sciences citoyennes, Neuchâtel, Editions Alphil, 93-97.

${ }^{28}$ I. Ajzen and M. Fishbein (2005), The Influence of Attitudes on Behavior, in D. Albarracin et al. (eds), The Handbook of Attitudes, Mahwah,NJ, Erlbaum, 173-222.

${ }^{29}$ The one-way analysis of variance on the four attitude variables ( 5 point Likert scale with NSP recoded in ni-ni) gave a p-value lower than 0.05 .

${ }^{30}$ Unfortunately the two studies do not measure the level of education in the same way: age at end of studies for the population survey and highest completed education for the evaluation of the festival. In the Swiss educational system secondary level I corresponds to the end of obligatory schooling (around 16 years), secondary level II includes general education and vocational courses, while the tertiary level includes university education and higher vocational training.

${ }^{31}$ The one-way analysis of variance on the four attitude variables ( 5 point Likert scale with NSP recoded in ni-ni) gave a p-value higher than 0.05 for the first three items, but lower than 0.05 for the last.

${ }^{32}$ Office of Science and Technology (OST) (2007); OST and Wellcome Trust (2000), Science and the Public. A Review of Science Communication and Public Attitudes to Science in Britain, London, OST.

\section{Author}

Fabienne Crettaz von Roten is senior scientist, head of research unit « Relations science-société » at the Observatoire Science, Politique et Societé, University of Lausanne, Switzerland. Her research offers a symmetrical view of the relations between science and society in Switzerland: population's attitudes and practices toward science and technology and scientists' attitudes and practices toward society. In her studies on the population, she assesses the three occurrences of the Swiss science festival.

E-mail: Fabienne.CrettazVonRoten@unil.ch.

How tO CITE: F. Crettaz von Roten, In search of a new public for scientific exhibitions or festivals: the track of casual visitors, Jcom 10(01) (2011) A02. 